\title{
In vitro antibacterial activity of poly (amidoamine)-G7 dendrimer
}

\author{
Mitra Gholami ${ }^{1}$, Rashin Mohammadi ${ }^{2}$, Mohsen Arzanlou $^{3}$, Fakhraddin Akbari Dourbash ${ }^{4}$, Ebrahim Kouhsari ${ }^{5}$, \\ Gharib Majidi ${ }^{6}$, Seyed Mohsen Mohseni ${ }^{7}$ and Shahram Nazari ${ }^{8^{*}}$
}

\begin{abstract}
Background: Nano-scale dendrimers are synthetic macromolecules that frequently used in medical and health field. Traditional anibiotics are induce bacterial resistence so there is an urgent need for novel antibacterial drug invention. In the present study seventh generation poly (amidoamine) (PAMAM-G7) dendrimer was synthesized and its antibacterial activities were evaluated against representative Gram- negative and Gram-positive bacteria.

Methods: PAMAM-G7 was synthesized with divergent growth method. The structural and surface of PAMAM-G7 were investigated by transmission electron microscopy, scanning electron microscope and fourier transform infrared. Pseudomonas. aeruginosa $(n=15)$, E. coli $(n=15)$, Acinetobacter baumanni $(n=15)$, Shigella dysenteriae $(n=15)$, Klebsiella pneumoniae $(n=10)$, Proteus mirabilis $(n=15)$, Staphylococcus aureus $(n=15)$ and Bacillus subtilis $(n=10)$ have been used for antibacterial activity assay. Additionally, representative standard strains for each bacterium were included. Minimum Inhibitory Concentration (MIC) was determined using microdilution method. Subsequently, Minimum Bactericidal Concentration (MBC) was determined by sub-culturing each of the no growth wells onto Mueller Hinton agar medium. The cytotoxicity of PAMAM-G7 dendrimer were evaluated in HCT116 and $\mathrm{NIH} 3 \mathrm{~T} 3$ cells by MTT assay.
\end{abstract}

Results: The average size of each particle was approximately $20 \mathrm{~nm}$. PAMAM-G7 was potentially to inhibit both Gram positive and gram negative growth. The MIC50 and MIC90 values were determined to be $2-4 \mu \mathrm{g} / \mathrm{ml}$ and $4-8 \mu \mathrm{g} / \mathrm{ml}$, respectively. The MBC50 and MBC90 values were found to be $64-256 \mu \mathrm{g} / \mathrm{ml}$ and $128-256 \mu \mathrm{g} / \mathrm{ml}$, respectively. The cytotoxity effect of dendrimer on $\mathrm{HCT} 116$ and $\mathrm{NIH} 3 \mathrm{~T} 3$ cells is dependent upon exposure time to and concentration of dendrimers. The most reduction (44.63 and 43\%) in cell viability for HCT116 and NIH 3 T3 cells was observed at the highest concentration, $0.85 \mu \mathrm{M}$ after $72 \mathrm{~h}$ treatmentm, respectively.

Conclusions: This study we conclude that PAMAM-G7 dendrimer could be a potential candidate as a novel antibacterial agent.

Keywords: Polyamidoamine-G7, Antibacterial activity, Gram-positive bacteria, Gram-negative bacteria, Cytotoxicity

\section{Background}

Healthcare associated infection (HCAI) presents a major problem for patient safety and could lead to prolonged hospitalization, long-term disability, high costs for patients and their families, and excess deaths $[1,2]$. In spite of the fact that modern medical science faces rapid advances, HCAIs still represent a worldwide public health issue and cause a significant additional financial

\footnotetext{
* Correspondence: shahramnazari73@yahoo.com

${ }^{8}$ Department of Environmental Health Engineering, Developmental Center for Student Research and Technology Talent, School of Public Health, Iran University of Medical Sciences, Tehran, Iran

Full list of author information is available at the end of the article
}

burden for the health system. The amount of annual financial lost due to HCAIs for Europe and USA are 7 billion euro and 6.5 billion dollars, respectively $[1,3]$. Multidrug-resistant (MDR) bacteria are reported as the main responsibility for treatment failure [4]. Methicillin resistant Staphylococcus aureus [5], extended-spectrum beta-lactamase-producing E. coli [6], carbapenem resistant Acinetobacter buamanii [4], and Pseudomonas aeruginosa [7] are the most important MDR's which are associated with these infection.

Among Shigella species, S. dysenteriae is of particular importance, because: (1) S. dysenteriae produces the Shiga 
toxin and causes severe infections; (2) $S$. dysenteriae is associated with large dysentery epidemics in developing countries; and (3) S. dysenteriae strains isolated worldwide are often MDR, with plasmid-mediated resistance to commonly used antimicrobials such as trimethoprimsulfamethoxazole, ampicillin, tetracycline and chloramphenicol $[8,9]$. Therefore, increment in the number of nosocomial infection by strains of MDR, the discovery and development of novel antibacterial agents, particularly those with structures and mechanisms of action different from traditional antibiotics, and a low potential to induce antibiotic resistance, are needed more than ever in the control and treatment of HCAIs. Compared to bulk materials, Nanoparticles (NPs) may be strategically advantageous as active antimicrobial agents, since NPs are excellent adsorbents, catalysts, and sensors due to their large surface area and high reactivity [10]. In addition, current antibiotics generally targets three organs consists of: cell wall, translation machinery and DNA replication system [11]. Unfortunately, each one of these modes of actions is susceptible to bacterial resistance. Various simulation processes such as production of reactive oxygen species, electrostatic interaction with the cell membrane, ion release, internalization and etc. contribute to NPs mode of action [12]. Cationic nano dendrimers have emerged as promising novel antibiotic agents in recent years $[13,14]$. Dendrimers are monodispersed, welldefined highly branched macromolecule, which exhibit an exponential increase in functional groups of each generation. Dendrimers have a highly branched threedimensional architecture with spaces between the branches and since these empty spaces can accept guest molecules, various size of particle can be encapsulated by dendrimers $[14,15]$. Due to the aforementioned properties, dendrimers have attracted great interest in exploring their potential biomedical applications such as drug delivery, gene transfection, and imaging [16, 17]. Recent research activities in this area include the study of antimicrobial activities of dendrimer derivatives. In most cases, biologically active agents can be encapsulated in the interior or, more often, tethered on the periphery of the dendrimers, therefore these dendrimers serve as carriers of biologically active agents. PAMAM dendrimers are the most extensively studied dendrimers. PAMAM dendrimers with a wide variety of functional groups at the periphery have the most antibacterial activity $[15,18]$. Their high potency antibacterial activity attributed to the electrostatic interaction between the cationic dendrimer and the anionic bacteria cell surface so it can be caused cell death due to the disruption of lipid bilayer. Thus, dendrimer biocides may be very beneficial in terms of activity, localization in specific organs, reduced toxicity, and increased duration of action $[16,17]$. The increasmen of generation of PAMAM dendrimers is followed by a double increase in the number of functional amine groups in the structure of dendrimer $[15,19]$. We designed a conceptional scheme of PAMAM-G7 dendrimer which shows the number of functional amino groups in each generation (Fig. 1a). The structure of PAMAM-G3 is also displayed in Fig. 1b.

Regarding the fact that bacteria cause hospital infections, also considering the MDR bacteria, evaluation of antibacterial properties of PAMAM dendrimers and taking the advantage of their ability as an

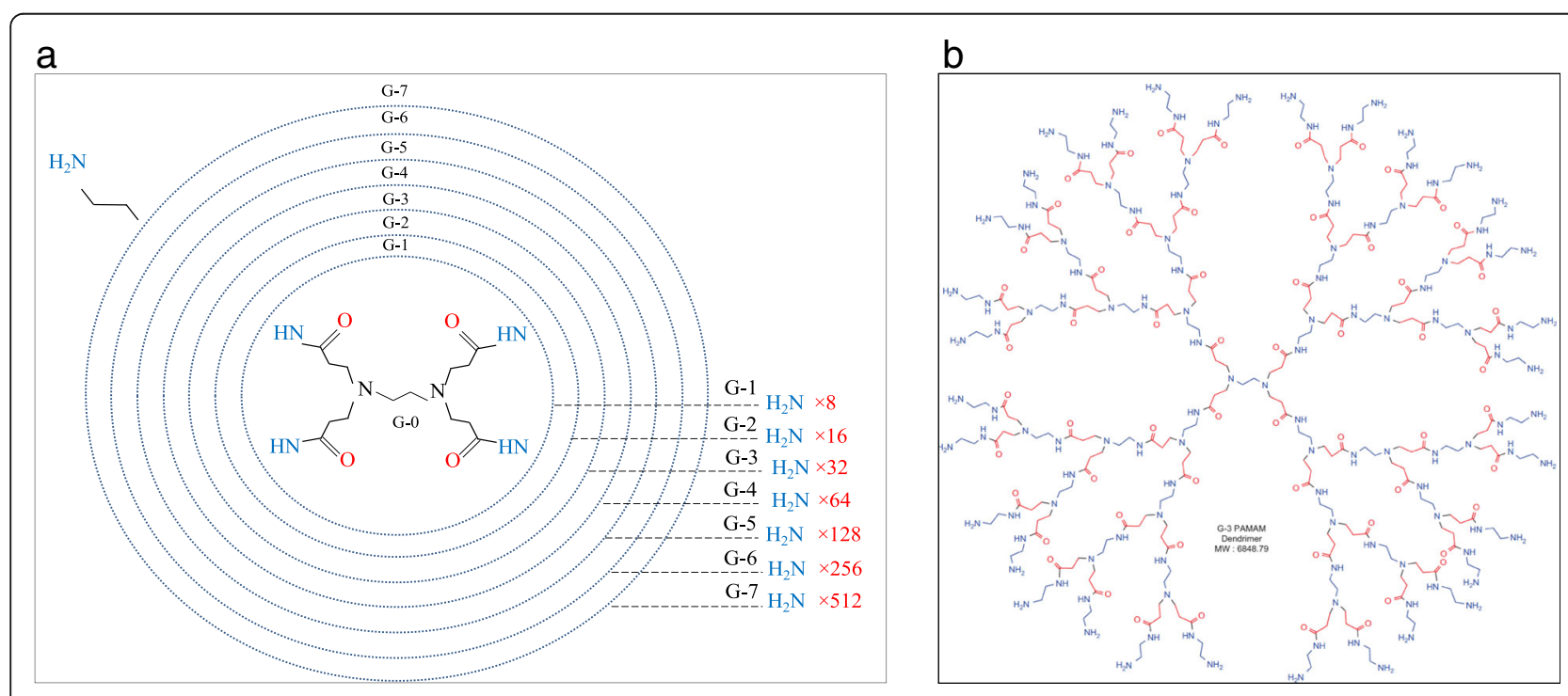

Fig. 1 a conceptional scheme of PAMAM-G7 dendrimer; $\mathbf{b}$ structure of PAMAM-G3 dendrimer 
antibacterial and antiseptic can be a research priority. Present study aimed to determine antibacterial properties of PAMAM-G7 dendrimer using disc diffusion, broth microdilution (MIC and MBC determination) methods. To our knowledge, this is the first report on the inherent high antibacterial PAMAM-G7 dendrimer which is not modified with common antibacterial agents. Overall, all of the dominant bacteria which are the main cause of HCAIs are investigated in current study.

\section{Methods}

\section{Bacterial strains}

In this study 8 bacterial species including Pseudomonas aeruginosa $(n=15)$, E. coli $(n=15)$, Acinetobacter baumanni $(n=15)$, Shigella dysenteriae $(n=15)$, Klebsiella pneumoniae $(n=10)$, Proteus mirabilis $(n=15)$, Staphylococcus aureus $(n=15)$ and Bacillus subtilis $(n=10)$ were selected. These bacteria have been isolated from clinical specimens and identified by conventional microbiological tests. Additionally, E. coli ATCC 25922, P. aeruginosa ATCC 27853, A. baumannii ATCC 17957, S. dysenteriae ATCC 13313, K. pneumoniae ATCC 1705, P. mirabilis ATCC 29906, S. aureus ATCC 25923 and B. subtilis ATCC 23857 were used as selected standard strains.

\section{Synthesis and characterization of poly (amidoamine)-G7 Dendrimer}

Ethylenediamine $(10 \mathrm{ml})$ was dissolved in $40 \mathrm{ml}$ ethanol in a 1-1 round-bottomed flask. Methyl acrylate $(112 \mathrm{ml})$ was added at $40{ }^{\circ} \mathrm{C}$ and stirred for $30 \mathrm{~h}$ in the presence of nitrogen exposure. The Excessive methyl acrylate was removed under vacuum condition room temperature. A Michael addition between the amine and the acrylate yielded a product bearing four terminal methyl ester groups, defined as the G0.5 PAMAM. Subsequently, ethylenediamine (1.04 gmol) was dissolved in ethanol, was added to the G0.5 PAMAM. Then, a product bearing four terminal amino groups was obtained and defined as the G1 PAMAM, after stirring for $48 \mathrm{~h}$ in the presence of nitrogen and removing excess reactants by vacuum distillation, seventh generation PAMAM dendrimers was synthesized by repeating the above cycle [20].

The chemical formula of PAMAM-G7 is $\mathrm{C}_{5102} \mathrm{H}_{10208}$ $\mathrm{N}_{2042} \mathrm{O}_{1020}$, molecular weight equal to $116,493 \mathrm{~g} / \mathrm{mol}$ and the number of terminal amine groups is 512 .

The molecular structure has clarify by Fourier transform infrared (FTIR, TENSOR 27 FTIR spectrometer, Bruker, Germany). Briefly, The samples were mixed with potassium bromide $(\mathrm{KBr})$ powder and then the mixtures were made into pellet under high pressure. The sample pellet was scanned from 400 to $4000 \mathrm{~cm}^{-1}$. Pure $\mathrm{KBr}$ acted as blank. The Morphology and size distribution of
PAMAM-G7 were analyzed by using transmission electron microscopy (TEM, Philips CM 30) and scanning electron microscope (SEM, Philips, XL30). For the TEM investigations, the samples were dispersed in ethanol and deposited by placing two drops of nanoparticle suspension onto carbon-covered copper-grids, followed by drying at room temperature. The structure of dendrimer was analyzed by scanning electron microscopy (SEM, Philips, XL30). The samples were prepared by mounting them on double sided carbon tape and coated with a thin layer of gold before imaging by sputtering method.

\section{Antibacterial activity assay}

The antibacterial activity of PAMAM-G7 dendrimer was determined by using disc diffusion method against clinical and standard bacterial strains as listed above. The $\mathrm{MIC}$ and $\mathrm{MBC}$ of the agents were determined by micro dilution method according to CLSI procedure [21].

\section{Disc diffusion method}

An overnight bacterial culture with the turbidity comparable to $0.5 \mathrm{Mc}$ Farland turbidity standard was prepared. The surface of a Mueller Hinton agar plate (4 cm diameter) was cultured uniformly with a sterilized cotton swab. Dried filter paper discs $(6 \mathrm{~mm}$ in diameter) containing $0.025,0.25,2.5$ and $25 \mu \mathrm{g} /$ disc were placed on the plate. Then, plates were incubated $24 \mathrm{~h}$ at $37^{\circ} \mathrm{C}$. The antibacterial activity was determined as the diameter of growth inhibition zone. In each plate a blank disc without the PAMAM-G7 was used as quality control.

\section{MIC and MBC testing}

MIC testing was carried out by using a microdilution method based on the method recommended by the Clinical Laboratory Standards Institute [21]. 2-fold serial dilutions of PAMAM-G7 dendrimer were prepared in sterile Mueller Hinton Broth (MHB) for a testing concentration range of $1-256 \mu \mathrm{g} / \mathrm{mL}$. Then $100 \mu \mathrm{L}$ from each dilution was transferred into the well of a microtiter plate and inoculated with $5 \mu \mathrm{L}$ of standardized $\left(1.5 \times 10^{7} \mathrm{CFU} / \mathrm{mL}\right)$ bacterial suspension. The microtiter plates were then incubated aerobically at $37{ }^{\circ} \mathrm{C}$ for $20-22 \mathrm{~h}$, and the lowest concentration of the agent that inhibited visible growth was recorded as the MIC. One well was used as a positive control for the all tested samples (only media, inoculum, no PAMAM-G7). Furthermore, another well was used as a negative control (only media, no inoculum, no PAMAM-G7).

MBC was determined by sub-culturing $10 \mu \mathrm{L}$ of broth from wells with no visible growth on nutrient agar plates. The number of colonies on agar were counted on a light board and compared to negative controls (only media, inoculum, no PAMAM-G7). The lowest concentration of 
PAMAM-G7 that killed $99.9 \%$ of the original inoculum was considered as MBC.

\section{Cytotoxicity assay}

To analyze the cytotoxicity effect, we used MTT assay on HCT116 and NIH 3 T3 cells [22] (human intestinal cancer cell line) which were purchased from the Pasteur Institute Cell Bank of Iran (http://ncbi.pasteur.ac.ir/). Briefly, 5000 cells suspended in 96-well plates diluted in $100 \mu \mathrm{L}$ RPMI 1640 media (Invitrogen, Carlsbad, CA) which were supplemented with 10\% heat-inactivated fetal bovine serum (FBS, Invitrogen, Carlsbad, CA), and $100 \mathrm{mg} / \mathrm{mL}$ penicillin-streptomycin (Invitrogen, Carlsbad, CA) at $37^{\circ} \mathrm{C}$ in a humidified atmosphere containing $5 \% \mathrm{CO}_{2}$. After $24 \mathrm{~h}$ that all cells attached to the baseline, $100 \mu \mathrm{L}$ of medium containing different concentration of PAMAM-G7 (0.043, 0.086, 0.17, 0.34, 0.515, 0.686 and $0.85 \mu \mathrm{M})$ were added to each determined well and incubated in above conditions for $48 \mathrm{~h}$ and $72 \mathrm{~h}$. After these incubation, $20 \mu \mathrm{L}$ containing $5 \mathrm{mg} / \mathrm{ml}$ MTT were added to the wells and incubated again for $4 \mathrm{~h}$. During this time, the MTT (yellow tetrazolium salt) was enzymatically converted into the purple formazan precipitate by viable cells that the concentration of formazan shows the proportional of viable cells. Subsequently, all medium was aspirated from the cells, then added $150 \mu \mathrm{l}$ DMSO to dissolve the formazan participates. Finally, absorbance was detected at $490 \mathrm{~nm}$ wavelength by ELISA plate reader. Controls were incubated for 48 and $72 \mathrm{~h}$ as a negative control and $0.002 \%$ benzalkonium chloride incubated for $30 \mathrm{~min}$ as a positive control.

\section{Statistical analysis}

Statistical analysis of data was performed using the Mann-Whitney U test analysis and Analysis of Variance (ANOVA). Statistical significance was assumed at $P<0.05$. Every experiment was repeated at least three independent times.

\section{Results}

The FTIR spectra of PAMAM-G7 dendrimer NPs were shown in Fig. 2. FTIR analysis of PAMAM-G7 NPs confirmed the existence of characteristic amides, terminal amino and etc. The data in Table 1 show the corresponding functional groups of the wavelengths indicated in Fig. 2.

According to the FTIR spectra, the double peaks of $\mathrm{NH}_{2}$ groups are located at $3200-3500 \mathrm{~cm}^{-1}(\mathrm{NH}$ stretching) and additional peaks at 1000-1350 and 1500-1630 $\mathrm{cm}^{-1}$ correspond to $\mathrm{C}-\mathrm{N}$ stretching and NH bending, respectively. The amide A band $\left(3407 \mathrm{~cm}^{-1}\right)$ originates from a combination of amide II stretching and $\mathrm{NH}$ in-plane bending vibrations of the PAMAM-G7. Furthermore, the protonated carboxylic

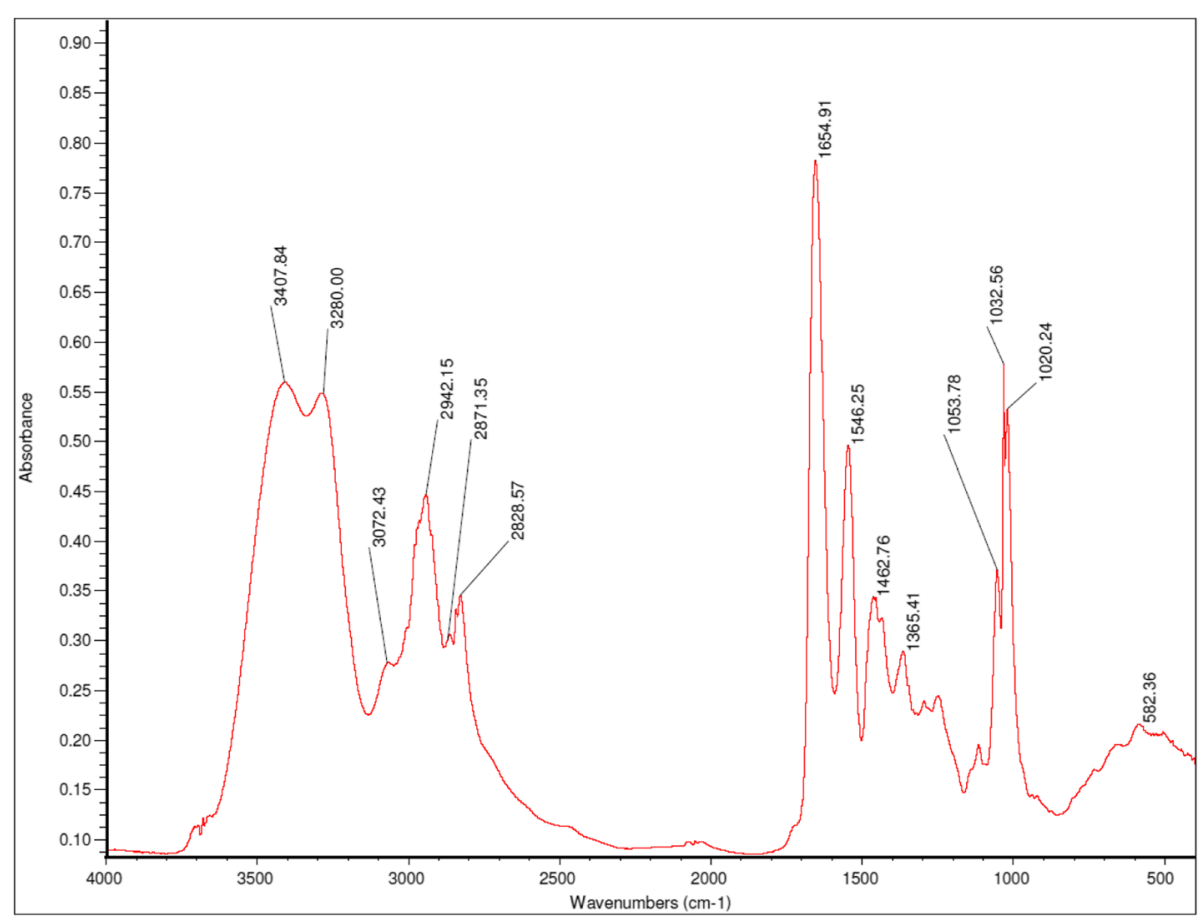

Fig. 2 FTIR spectra of PAMAM-G7 
Table 1 Band position of PAMAM-G7 spectrum

\begin{tabular}{ll}
\hline Band position $\left(\mathrm{cm}^{-1}\right)$ & Assignment \\
\hline 1032.56 & $\mathrm{C}-\mathrm{O}$ stretching vibration \\
1654.91 & $\mathrm{C}=\mathrm{O}$ stretching (amide I) \\
1546.25 & $\mathrm{~N}-\mathrm{H}$ bending/C-N stretching (amide II) \\
1462.78 & $\mathrm{H}-\mathrm{C}-\mathrm{H}$ scissor \\
1365.41 & $\mathrm{H}-\mathrm{C}-\mathrm{H}$ asymmetric \\
$2828.57 \mathrm{and} 2942.15$ & $\mathrm{C}-\mathrm{H}$ stretching \\
$3407.84 \mathrm{~cm}^{-1}$ and & $\mathrm{N}-\mathrm{H}$ stretching mode of amine I and \\
3280 & amide groups \\
\hline
\end{tabular}

acids is characterized by absorption bands corresponding to a carbonyl stretch $(\mathrm{C}=\mathrm{O})$ between 1690 and $1750 \mathrm{~cm}$ ${ }^{-1}$, and $\mathrm{C}-\mathrm{OH}$ vibrations between 1200 and $1300 \mathrm{~cm}^{-1}$. Upon deprotonation, the vibrational mode of $\mathrm{C}=\mathrm{O}$ becomes coupled to that of the other deprotonated oxygen and its energy shifts to a lower energy level. This gives rise to an asymmetric stretching feature between 1550 and $1660 \mathrm{~cm}^{-1}$. The $\mathrm{C}-\mathrm{OH}$ band also shifts to higher energies upon deprotonation, giving rise to a symmetric $\mathrm{COO}^{-}$ mode between 1300 and $1420 \mathrm{~cm}^{-1}$ as can be seen from the FTIR spectra. The TEM images of the PAMAM-G7 dendrimer NPs is shown in Fig. 3 PAMAM-G7 NPs were shown to have a spherical shape with a mean diameter size of $20 \mathrm{~nm}$. Figure 4 shows SEM image of the PAMAM-G7 NPs. The SEM image demonstrates that PAMAM-G7 NPs are nearly spherical. It also displays multi-layered -like structure, which has smaller spherical substructures. The results of different concentrations of PAMAM-G7 dendrimer effect on isolated bacteria and standard strains (using disc diffusion method) are shown in Tables 2 and 3, respectively. According to the obtained results, PAMAM-G7 dendrimer actively inhibited the growth of isolated Gram-negative and Gram-positive bacteria and standard strains. However, the antibacterial

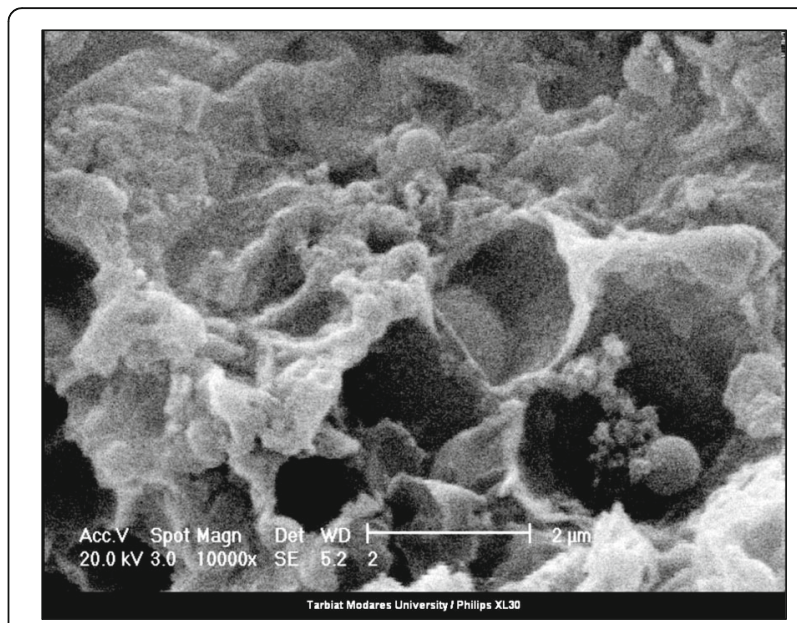

Fig. 4 SEM Image of the PAMAM-G7

activity of PAMAM-G7 on the isolated bacteria was less than that on the standard strains.

It was also a statistically significant difference $(p<0.05)$. The most of sensitivity related to $P$. mirabilis ATCC 29906, S. dysenteriae ATCC 13313 and S. aureus ATCC 25923 at concentration of $25(\mu \mathrm{g} / \mathrm{disc})$ PAMAM-G7 with zone of inhibition 36,32 and $31 \mathrm{~mm}$, respectively. In addition, the least sensitivity is related to A. baumannii at $25(\mu \mathrm{g} / \mathrm{disc})$ concentration of dendrimer with $13 \mathrm{~mm}$ zone of inhibition. The concentration of $0.025(\mu \mathrm{g} / \mathrm{disc})$ dendrimer had no effect on the studied bacteria, except P. mirabilis and S. aureus.

The MIC50 and MIC90 values for all selected bacteria were determined $2-4 \mu \mathrm{g} / \mathrm{ml}$ and $4-8 \mu \mathrm{g} / \mathrm{ml}$ respectively (Table 4). The MBC50 and MBC90 values were found to be $64-256 \mu \mathrm{g} / \mathrm{ml}$ and $128-256 \mu \mathrm{g} / \mathrm{ml}$, respectively (Table 5). The highest MIC50 and MIC90 values for the clinical isolates were 4 and $8 \mu \mathrm{g} / \mathrm{ml}$,
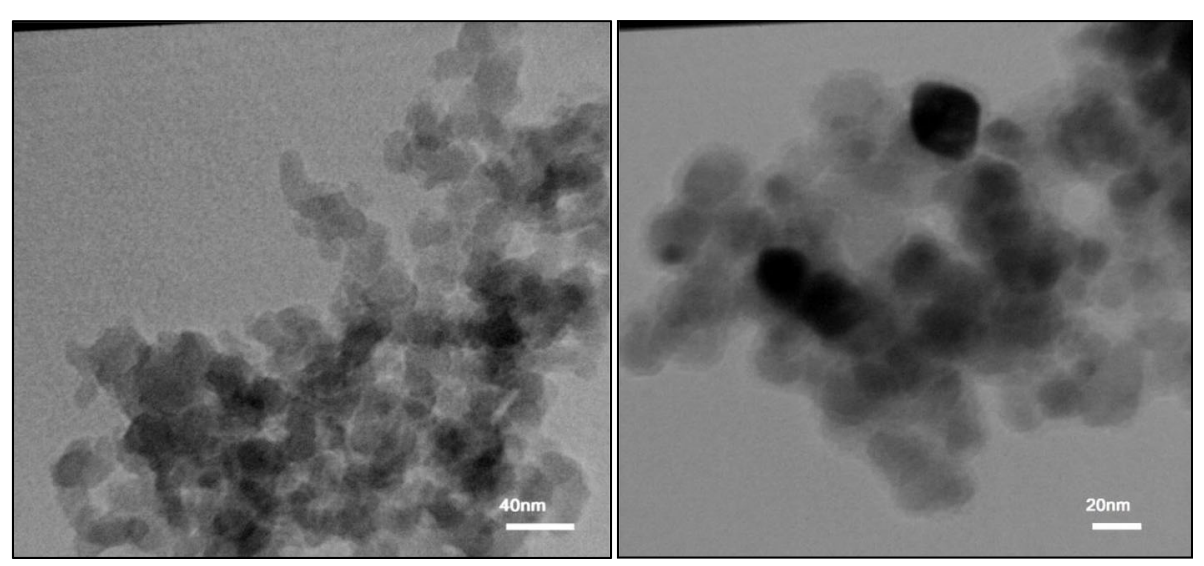

Fig. 3 TEM Image of the PAMAM-G7 at different magnifications 
Table 2 The mean and confidence interval for inhibition zone diameter of isolated bacteria VS different PAMAM-G7 dendrimer concentrations

\begin{tabular}{|c|c|c|c|c|c|c|c|c|}
\hline \multirow{2}{*}{$\begin{array}{l}\text { Dendrimer } \\
\text { concentration, } \\
\mu \mathrm{g} / \text { disc }\end{array}$} & \multicolumn{8}{|c|}{ Zone of inhibition, mm, [Mean (CI)] } \\
\hline & E. coli & A.baumannii & K. pneumoniae & S. dysenteriae & P. aeruginosa & P. mirabilis & B. subtilis & S. aureus \\
\hline 0.025 & 0 & 0 & 0 & 0 & 0 & $10(8.16,11.84)$ & 0 & $10(8.16,11.84)$ \\
\hline 0.25 & 0 & 0 & $17(16.08,17.92)$ & 0 & 0 & $19(16.23,21.44)$ & $9(8.08,9.92)$ & $11(8.56,13.44)$ \\
\hline 2.5 & 0 & 0 & $19(18.08,19.92)$ & $14(12.16,15.84)$ & 0 & $22(19.56,24.44)$ & $9(7.4,10.6)$ & $11(7.8,14.2)$ \\
\hline 25 & $22(20.4,23.6)$ & $13(11.6,14.4)$ & $27(24.56,29.44)$ & $30(27.56,32.44)$ & $24(21.23,26.77)$ & $33(31.4,34.6)$ & $18(16.4,19.6)$ & $22(19.56,24.44)$ \\
\hline
\end{tabular}

respectively (Table 4). This was found in E. coli, A. baumannii, $P$. aeruginosa and $S$. aureus isolates.

Table 4 also shows that the least amount of MIC50 and MIC90 were related to $S$. dysenteriae and P. mirabilis $(2 \mu \mathrm{g} / \mathrm{ml})$. Table 5 shows that the highest MBC50 and MBC90 values were related to $E$. coli, $P$. aeruginosa and $S$. aureus $(256 \mu \mathrm{g} / \mathrm{ml})$. Moreover, it can be seen from Table 5 that the least amount of MBC50 and MBC90 with 64 and $128 \mu \mathrm{g} / \mathrm{ml}$, respectively, are of the bacteria $S$. dysenteriae. In addition, the MIC and MBC of the standard bacteria were also studied. MIC was found to be $4 \mu \mathrm{g} / \mathrm{ml}$ for $E$. coli ATCC 25922, A. baumannii ATCC 17957, P. aeruginosa ATCC27853, S. aureus ATCC 25923 and $2 \mu \mathrm{g} / \mathrm{ml}$ for $K$. pneumoniae ATCC 49131, S. dysenteriae ATCC 13313, P. mirabilis ATCC 29906 and B. subtilis ATCC 23857. Besides, MBC for $E$. coli ATCC 25922, A. baumannii ATCC 17957, P. aeruginosa ATCC27853, S. aureus ATCC 25923 and K. pneumoniae ATCC 49131 was $128 \mu \mathrm{g} / \mathrm{ml}$ and for $S$. dysenteriae ATCC 13313, P. mirabilis ATCC 29906 and B. subtilis ATCC 23857 was seen to be $64 \mu \mathrm{g} / \mathrm{ml}$.

The profiles of cytotoxicity of PAMAM-G7 against HCT116 and NIH 3 T3 cells after 48 and 72 h treatment are shown in Figs. 5 and 6, respectively.

Figures 5 and 6 also indicate that, by the increase of concentration and exposure time to PAMAM-G7 dendrimer, cytotoxicity gradually increases. Moreover, statistical results of ANOVA showed that in the exposure times of 48 and $72 \mathrm{~h}$, the cytotoxicity of PAMAM-G7 dendrimer in all the concentrations and towards both cell lines was significantly increased in comparison to the negative control $(P<0.05)$. So, by the increase of
PAMAM-G7 dendrimer concentration from 0.043 to $0.85 \mu \mathrm{M}$, cell viability (HCT116) declined after 48 and $72 \mathrm{~h}$ from 86.93 to $70.66 \%$ and 82.8 to $55.37 \%$, respectively. Also for NIH 3 T3 cells in the same conditions, cell viability declined after 48 and $72 \mathrm{~h}$ from 87.63 to $68.5 \%$ and 83.9 to $57 \%$, respectively. However, there are relatively low cytotoxicity effects of PAMAM-G7 with different concentrations towards HCT 116 and $\mathrm{NIH}$ 3 T3 cells during 48 and $72 \mathrm{~h}$, where no IC50 value was obtained. Also, in the range of MIC value the cytotoxicity of PAMAM-G7 on both cell lines was relatively low.

\section{Discussion}

Today modern hospitalization is the occurrence of nosocomial or healthcare acquired infections caused by MDR pathogens [23]. PAMAM dendrimers have been investigated for their biological applications, but antibacterial activity has not been extensively explored [17, 24]. In this work, we used disc diffusion and broth microdilution (MIC and MBC determination) methods to assess the antibacterial activity of PAMAM-G7 against eight most common human pathogens isolated from clinical specimens, as well as standard strains. S. aureus is a microorganism causing a wide range of infections from local infections of skin and soft tissue to pneumonia and endocarditis [25]. A. baumannii is an important human pathogen causing hospital-acquired infections, such as ventilator associated pneumonia, bacteremia, meningitis, urinary tract, and wound infections [26]. E. coli strains are responsible for several forms of diarrheal disease [27] and meningitis in neonates [28]. P. aeruginosa is

Table 3 The mean and confidence interval for inhibition zone diameter of standard strains VS different PAMAM-G7 dendrimer concentrations

\begin{tabular}{|c|c|c|c|c|c|c|c|c|}
\hline \multirow{2}{*}{$\begin{array}{l}\text { Dendrimer } \\
\text { concentration, } \\
\mu \mathrm{g} / \text { disc }\end{array}$} & \multicolumn{8}{|c|}{ Zone of inhibition, mm, [Mean (Cl)] } \\
\hline & $\begin{array}{l}\text { E. coli } \\
\text { ATCC } 25922\end{array}$ & $\begin{array}{l}\text { A. baumanniiATCC } \\
7,957\end{array}$ & $\begin{array}{l}\text { K. pneumoniae } \\
\text { ATCC } 49131\end{array}$ & $\begin{array}{l}\text { S. dysenteriae } \\
\text { ATCC } 13313\end{array}$ & $\begin{array}{l}P . \text { aeruginosa } \\
\text { ATCC27853 }\end{array}$ & $\begin{array}{l}\text { P. mirabilis } \\
\text { ATCC } 29906\end{array}$ & $\begin{array}{l}\text { B. subtilis } \\
\text { ATCC } 23857\end{array}$ & $\begin{array}{l}\text { S. aureus } \\
\text { ATCC } 25923\end{array}$ \\
\hline 0.025 & 0 & 0 & 0 & 0 & 0 & $12(10.6,12.7)$ & 0 & $12(10.6,13.41)$ \\
\hline 0.25 & 0 & $10(9,10.9)$ & $20(16.77,23.33)$ & $15(13.4,16.6)$ & 0 & $21(18.7,22.58)$ & $9(7.59,10.41)$ & $13(12,13.9)$ \\
\hline 2.5 & $10(9,10.9)$ & $14(13,14.9)$ & $21(20.08,21.92)$ & $20(18.6,20.72)$ & $9(8.08,9.92)$ & $24(22.2,25)$ & $10(8.9,11)$ & $19(17.6,20.4)$ \\
\hline 25 & $26(25,26.9)$ & $20(17.2,22.8)$ & $29(28.08,29.92)$ & $32(30.6,33.4)$ & $25(22.7,26.5)$ & $36(35.08,36.9)$ & $22(21,22.9)$ & $31(30.47,31.53)$ \\
\hline
\end{tabular}


Table 4 MIC of the PAMAM-G7 dendrimer for isolated bacteria

\begin{tabular}{|c|c|c|c|c|c|c|}
\hline \multirow[t]{2}{*}{ Bacteria spp } & \multicolumn{4}{|c|}{ MIC $(\mu \mathrm{g} / \mathrm{ml}) \mathrm{n}(\%)$} & \multirow{2}{*}{$\begin{array}{l}\text { MIC } \\
50\end{array}$} & \multirow{2}{*}{$\begin{array}{l}\mathrm{MIC} \\
90\end{array}$} \\
\hline & 1 & 2 & 4 & 8 & & \\
\hline E. coli & & & $10(66.7)$ & $5(33.3)$ & 4 & 8 \\
\hline A. baumannii & & & $9(60)$ & $6(40)$ & 4 & 8 \\
\hline K. pneumoniae & & & $7(70)$ & $3(30)$ & 2 & 4 \\
\hline S. dysenteriae & $5(33.3)$ & $10(66.7)$ & & & 2 & 2 \\
\hline P. aeruginosa & & & $12(80)$ & $3(20)$ & 4 & 8 \\
\hline P. mirabilis & $3(20)$ & $12(80)$ & & & 2 & 2 \\
\hline B. subtilis & & $1(10 \%)$ & $9(90)$ & & 4 & 4 \\
\hline S. aureus & & & $10(66.6)$ & $5(33.3)$ & 4 & 8 \\
\hline
\end{tabular}

inherently resistant to drugs because of its less permeable cell wall and a variety of efflux pumps [29]. K. pneumoniae can be found commonly in humans and animals' mouth, skin, and intestines as an opportunistic pathogen, frequently causing pneumonia, infection of the urinary tract, and soft tissues [30].

The infections caused by $S$. dysenteriae and Proteus mirabilis had a serious clinical problem. S. dysenteriae is the cause of brisk and deadly epidemics and pose major health problems in the poorest populations. Alternative therapeutic strategies are necessarily in search due to the emergence of MDR in Shigellae [31]. Antibacterial properties of PAMAM-G7 dendrimer was checked also against B. subtilis. B. subtilus is not a common HCAI organism, but it was used as a representative for sporeforming bacteria [32]. The size of the inhibition zone clearly shows that with increasing concentrations of the PAMAM-G7 NPs, the surrounding zone of the discs is expanded (Tables 2 and 3). The results of this study showed that very low concentrations $(0.025 \mu \mathrm{g} / \mathrm{disc})$ of the dendrimer PAMAM-G7 inhibits the growth of the $P$. mirabilis and S. aureus isolates (Tables 2 and 3). The study carried out by Izanloo et al. [33], by disc diffusion method on the effect of dendrimer PAMAM-G4 on $E$. coli, Enterobacter cloacae, B. subtilis and S. aureus,

Table $5 \mathrm{MBC}$ of the PAMAM-G7 dendrimer for isolated bacteria

\begin{tabular}{|c|c|c|c|c|c|}
\hline \multirow[t]{2}{*}{ Bacteria spp } & \multicolumn{3}{|c|}{$\mathrm{MBC}(\mu \mathrm{g} / \mathrm{ml}) \mathrm{n}(\%)$} & \multirow{2}{*}{$\begin{array}{l}\text { MBC } \\
50\end{array}$} & \multirow{2}{*}{$\begin{array}{l}\text { MBC } \\
90\end{array}$} \\
\hline & 64 & 128 & 256 & & \\
\hline E. coli & & $3(20)$ & $12(80)$ & 256 & 256 \\
\hline A. baumannii & & $9(60)$ & $6(40)$ & 128 & 256 \\
\hline K. pneumoniae & & $7(70)$ & $3(30)$ & 128 & 256 \\
\hline S. dysenteriae & $9(60)$ & $6(40)$ & & 64 & 128 \\
\hline P. aeruginosa & & $2(13)$ & $13(87)$ & 256 & 256 \\
\hline P. mirabilis & $3(20)$ & $12(80)$ & & 128 & 128 \\
\hline B. subtilis & $1(10)$ & $9(90)$ & & 128 & 128 \\
\hline S. aureus & & $5(33)$ & $10(67)$ & 256 & 256 \\
\hline
\end{tabular}

concluded that concentration of $0.05 \mu \mathrm{g} /$ disc has no effect on these bacteria and it was shown that the antibacterial effect of PAMAM-G4 takes place in higher concentrations. Izanloo et al. [34], in another study which was carried out by disc diffusion method and was aimed to evaluate the effect of PAMAM-G4 dendrimer on Klebsiella oxytoca, $P$. mirabilis and $P$. aeruginosa, has showed that concentrations of $0.5,5$ and $50 \mu \mathrm{g} /$ disc of PAMAM-G4 has no effect on these selected bacteria. Probably, the higher antibacterial effect of PAMAM-G7 dendrimer in comparison to lower generation dendrimers can be attributed to high density, ordered, hyper branching structure, high spatial void between branches, large number of terminal functional groups and relatively large molecular size of PAMAM-G7 [24]. These characteristics lead to high surface area in dendrimer PAMAM-G7 which causes higher activity of dendrimers in surface of culture and higher efficiency at lower concentrations. Figure 4 shows a SEM image of dendrimer PAMAM-G7. Because of their multi-layered structures with high purity, they can trap and absorb many microbial agents. Dendritic structures known as dendriform with progressive structure are illustrated in this figure. Too many branches of this dendriform lead to increase in the dendrimer surface area therefore they absorb microbes on their surface. On the other hand, nano holes created between branches trap biological agents and destroy them. But most importantly, it is the number of terminal amine groups, which for generation 4 is 64, while the number of terminal amine groups for PAMAM-G7 is 512 (http://www.dendritech.com/ pamam.html) [35]. These functional groups are adsorbed on the bacterial cell surfaces, diffused through the cell wall, bonded to cytoplasmic membrane and release electrolytes such as potassium ions and phosphate from the cell, also nucleic materials such as DNA and RNA due to disruption and disintegrate of the cytoplasmic membrane. Therefore it is proposed that the antibacterial property of dendrimers is mediated by disrupting the bacterial outer and inner membrane by terminal amine groups $[17,36]$.

According to MIC or MBC values (Tables 4 and 5), it is clear that PAMAM-G7 has antibacterial effects and can be used as antibacterial agent. Previous studies have been shown that these antibacterial agents cause bacterial cell membrane damage, spatial deformation, degradation of bacterial enzymes, damage of chromosome and bacteria cell wall damage [15, 37]. This character refers to end amine groups in dendrimer structure which interact with negative charge of membrane or microorganism cytoplasm, causing bacterial cell wall damage and finally, inactivation of bacteria [16]. Figure 2 shows the FTIR spectra of PAMAM-G7 dendrimer. As shown, 9 peaks are detectable at $1032 \mathrm{~cm}^{-1}, 1365 \mathrm{~cm}^{-1}, 1462 \mathrm{~cm}^{-1}, 1546 \mathrm{~cm}$ 


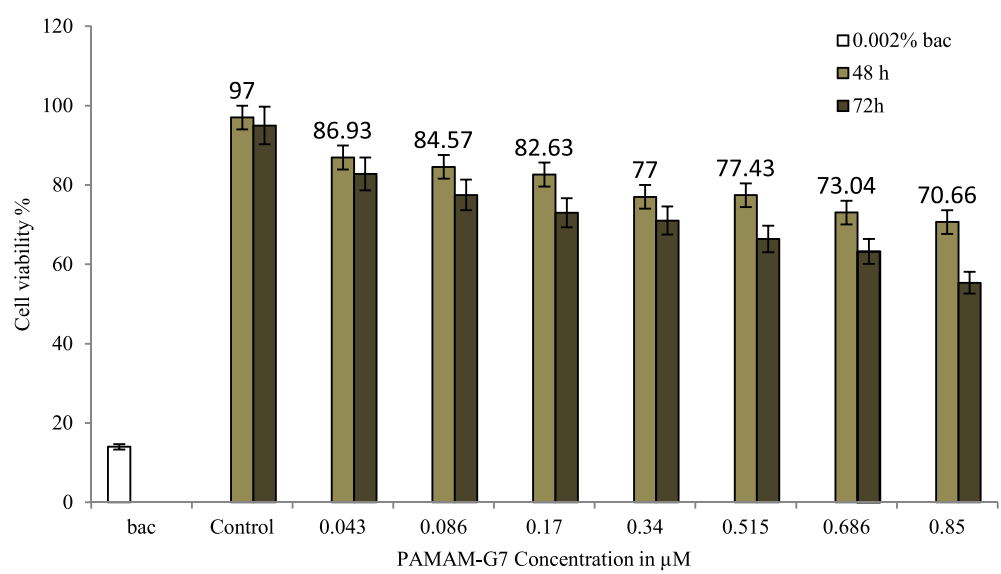

Fig. 5 PAMAM-G7 cytotoxicity to HCT116 cells measured by MTT survival assay in $48 \mathrm{~h}$ and $72 \mathrm{~h}$ with $0.002 \%$ benzalkonium chloride (bac) as the positive control. Percent survival of HCT116 cells upon treatment with PAMAM-G7 at various concentrations is based on an untreated control. The data show the mean from two separate experiments ( $48 \mathrm{~h}$ and $72 \mathrm{~h}$ ) with three replicates per condition, and the error bar represents a standard deviation

$-1,1654 \mathrm{~cm}^{-1}, 2828 \mathrm{~cm}^{-1}, 2942 \mathrm{~cm}^{-1} 3280 \mathrm{~cm}^{-1}$ and $3407 \mathrm{~cm}^{-1}$ which the last peak is related to $\mathrm{N}-\mathrm{H}$ stretching vibration of primary amine. Other main band positions, based on wavenumber, and their assignments are presented in Table 1.

Thus, the PAMAM-G7 dendrimer is an efficient antibacterial agent for both Gram-negative and Grampositive bacteria. Chen et al. [38], observed the antibacterial effect of polypropyleneimine dendrimer modified with quaternary ammonium groups on Gram-positive and Gram-negative bacteria. Likewise, Xue. et al. and Charles. et al., have shown that amino-terminated PAMAM-G2 and G3 dendrimers possess significant antibacterial effects on MDR strains [14, 15].
As shown in Tables 2, 3, 4 and 5, the E. coli, P. aeruginosa, $A$. baumannii and $S$. aureus had a higher resistance than other studied bacteria. Probably the effect of lower concentrations of dendrimer PAMAM-G7 on the bacteria such as E. coli, P. aeruginosa, A. Baumannii and S. aureus than other target bacteria can be due to intrinsic resistance of these bacteria $[5,39,40]$.

Also, the cytotoxicity of PAMAM-G7 was investigated on HCT 116 and NIH 3 T3 cell lines (mammalian cells). The obtained data (Figs. 5 and 6) show that by increasing both concentration and exposure time the cytotoxity effect on target cells increases.

Mukherjee et al. [22] indicated different generations (G4, G5 and G6) of PAMAM dendrimers with variety of

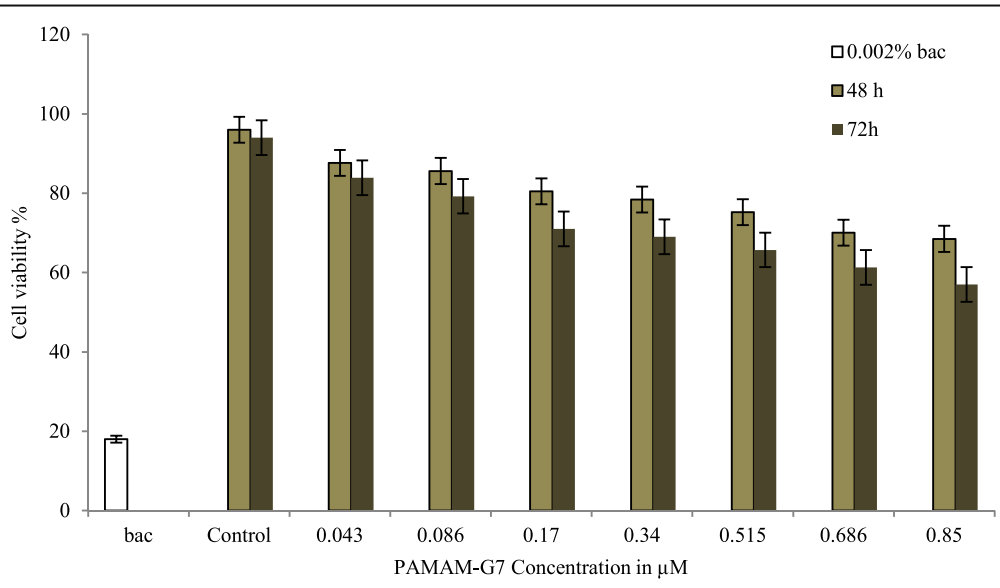

Fig. 6 PAMAM-G7 cytotoxicity to NIH 3 T3 cells measured by MTT survival assay in $48 \mathrm{~h}$ and $72 \mathrm{~h}$ with $0.002 \%$ benzalkonium chloride (bac) as the positive control. Percent survival of NIH 3 T3 cells upon treatment with PAMAM-G7 at various concentrations is based on an untreated control. The data show the mean from two separate experiments ( $48 \mathrm{~h}$ and $72 \mathrm{~h}$ ) with three replicates per condition, and the error bar represents a standard deviation 
doses which increasing dose and generation of these dendrimers cause decrease in the percentage of healthy and early apoptotic cell which increasing dose and generation of these dendrimers cause decrease in the percentage of healthy and early apoptotic cell. At high concentrations, PAMAM can lead to the formation of nanoscale holes in eukaryotic membranes [22, 41, 42]. Highly branched cationic polymers permeate eukaryotic membranes better than linear molecules, such as LL-37 [42], so PAMAM dendrimers are more toxic for eukaryotic cells. This property of branched polymers has been widely used in foreign gene or drug transfaction in eukaryotic cells [17]. The charge density on the polymer also plays an important role in permeability [42]. After $72 \mathrm{~h}$ of treatment at the highest concentration of PAMAM-G7 $(0.85 \mu \mathrm{M}), 55.37$ and $57 \%$ of HCT116 and NIH 3 T3 cells survived, respectively (Figs. 5 and 6). The value of obtained MIC50, MIC90 (2-4 and 4-8 $\mu \mathrm{g} / \mathrm{ml}$, respectively) and MIC for standard strains $(2 \mu \mathrm{g} / \mathrm{ml})$ for both Gram-positive and Gram-negative bacteria, showed, PAMAM-G7 at relatively lower concentrations, has high toxic effect on both Gram-negative and Grampositive bacteria.

However in $0.086 \mu \mathrm{M}(10 \mu \mathrm{g} / \mathrm{ml})$ PAMAM-G7 and after 48 and 72 h, 84 and 77\% of HCT 116 cells were survived, respectively (Fig. 5). Also in same condition 85.61 and $79.24 \%$ of NIH 3 T3 cells were survived, respectively (Fig. 6).

Furthermore the most important attachment is great toxicity of PAMAM-G7 on Gram-negative and Gram positive bacteria. However PAMAM-G7 has relatively low toxicity on HCT 116 and NIH 3 T3 cells. To further elucidate this observation, it was noted that the polycationic PAMAM molecules prefer to bind to bacteria cells that carry a higher density of negative charges on their surfaces rather than eukaryote cell lines.

Initial electrostatic interaction, followed by further interactions, including hydrophobic interactions between the dendrimers and cell membrane, are shown to be necessary to cause cell lysis, since it has been shown that surfaces presenting a high density of amino groups have no marked effect on the membrane of the attached bacteria $[17,42]$.

However, various studies have shown that, PAMAM dendrimers show relatively high toxicity against various eukaryotic cells. But the notable point is that, most studies regarding the use of PAMAM dendrimers, are in the field of drug delivery and gene transfection. The high amount of dendrimers is required on drug and gene delivery so, such studies indicate the high toxic effect of PAMAM dendrimers on eukaryotic $[43,44]$, the cytotoxicity of PAMAM dendrimers, often investigates in higher concentrations. In a study the toxic effect of different PAMAM dendrimers (G3, 3.5, 4, 4.5, and) generations on HepG2 and DU145 cell lines was investigated. It indicate, HepG2 were less sensitive than DU145 cells with IC50 values $\geq 402 \mu \mathrm{M}$ (PAMAMs) and $\leq 13.24 \mu \mathrm{M}$ (PAMAMs) for DU145 [45]. In another study the cytotoxicity of various PAMAM dendrimers (G4, G5, G6) generations on $\mathrm{HaCaT}$ and SW480 cells was measured by MTT assay, after $24 \mathrm{~h}$ exposure it was found that, EC50 concentrations for PAMAM G4, G5 and G6 in SW480 cells were equal to $1.44,0.37$ and $1.16 \mu \mathrm{M}$, respectively, and for $\mathrm{HaCaT}$ cells were equal to $1.02,1.07$, and $3.21 \mu \mathrm{M}$, respectively [22].

\section{Conclusion}

The results of this study showed PAMAM-G7 dendrimer has good antibacterial activity against both Gram-positive and Gram-negative bacteria. We think this compound can be implemented as an antiseptic and disinfectant agent in health sections. In addition, in the MIC value range, the cytotoxicity effect of PAMAM-G7 on HCT 116 and NIH 3 T3 cells was relatively lower. So, PAMAM-G7 could be an excellent candidate as new class of antibacterial compounds for control of bacterial infections. However to achieve this goal further studies are needed.

\section{Abbreviations \\ CLSI: Clinical and laboratory standards institute; FTIR: Fourier transform infrared; HCAl: Healthcare associated infection; IROST: Iranian research organization for science and technology; MBC: Minimum bactericidal concentrations; MDR: Multi-drug resistant; MIC: Minimum inhibitory concentration; NPs: Nanoparticles; PAMAM-G7: Polyamidoamine-G7; SEM: Scanning electron microscope; TEM: Transmission electron microscopy}

\section{Acknowledgements \\ The authors gratefully acknowledge all the support for this study that was provided by student research committee, school of public health, Iran University of Medical Sciences, Tehran, Iran.}

\section{Funding}

This work was supported by funding from student research committee, school of public health, Iran University of Medical Science, Tehran, Iran, in the form of junior research fellowship (95-02-193-26,215).

\section{Availability of data and materials}

The dataset supporting the conclusions of this article are shown throughout the text.

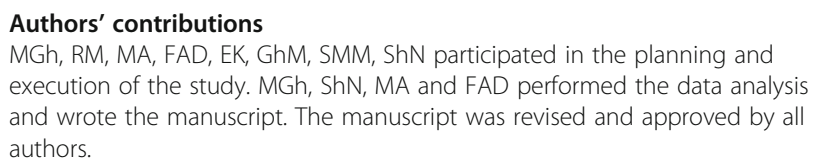

Competing interests

The authors declare that they have no competing interests.

Consent for publication

Not applicable

Ethics approval and consent to participate

Not applicable 


\section{Publisher's Note}

Springer Nature remains neutral with regard to jurisdictional claims in published maps and institutional affiliations.

\section{Author details \\ 'Department of Environmental Health Engineering, School of public Health, Iran University of Medical Sciences, Tehran, Iran. ${ }^{2}$ Department of Life Science Engineering, Faculty of New Science and Technology, University of Tehran, Tehran, Iran. ${ }^{3}$ Department of Microbiology, School of Medicine, Ardabil University of Medical Sciences, Ardabil, Iran. ${ }^{4}$ Department of Materials science and Engineering, Tarbiat Modares University, Tehran, Iran. ${ }^{5}$ Department of Microbiology, School of Medical, Iran University of Medical Sciences, Tehran, Iran. ${ }^{6}$ Department of Environmental Health Engineering, School of public Health, Qom University of Medical Sciences, Qom, Iran. ${ }^{7}$ Department of Environmental Health Engineering, School of public Health, Shahid Beheshti University of Medical Sciences, Tehran, Iran. ${ }^{8}$ Department of Environmental Health Engineering, Developmental Center for Student Research and Technology Talent, School of Public Health, Iran University of Medical Sciences, Tehran, Iran.}

Received: 20 February 2017 Accepted: 1 June 2017

\section{Published online: 05 June 2017}

\section{References}

1. Allegranzi B, Nejad SB, Combescure C, Graafmans W, Attar H, Donaldson L, et al. Burden of endemic health-care-associated infection in developing countries: systematic review and meta-analysis. Lancet. 2011;377(9761):228-41.

2. Dramowski A, Whitelaw A, Cotton M. Burden, spectrum, and impact of healthcare-associated infection at a south African children's hospital. J Hosp Infect. 2016:94(4):364-72

3. Chen Y, Zhao J, Shan X, Han X, Tian S, Chen F, et al. A point-prevalence survey of healthcare-associated infections in 52 Chinese hospitals. J Hosp Infect. 2016:40(6):491-6.

4. Rajamohan G, Srinivasan V, Gebreyes W. Biocide-tolerant multidrug-resistant Acinetobacter Baumannii clinical strains are associated with higher biofilm formation. J Hosp Infect. 2009;73(3):287-9.

5. Jannati E, Arzanlou M, Habibzadeh S, Mohammadi S, Ahadi $P$, Mohammadi-Ghalehbin B, et al. Nasal colonization of mecA-positive, oxacillin-susceptible, methicillin-resistant Staphylococcus aureus isolates among nursing staff in an Iranian teaching hospital. Am J Infect Control. 2013;41(11):1122-4.

6. Banerjee R, Robicsek A, Kuskowski MA, Porter S, Johnston BD, Sokurenko E, et al. Molecular epidemiology of Escherichia coli sequence type 131 and its $\mathrm{H} 30$ and $\mathrm{H} 30-\mathrm{Rx}$ subclones among extended-spectrum- $\beta$-lactamase-positive and-negative E. coli clinical isolates from the Chicago region, 2007 to 2010. Antimicrob Agents Chemother. 2013;57(12):6385-8.

7. Zavascki AP, Carvalhaes CG, Picão RC, Gales AC. Multidrug-resistant Pseudomonas Aeruginosa and Acinetobacter Baumannii: resistance mechanisms and implications for therapy. Expert Rev Anti-Infect Ther. 2010;8(1):71-93.

8. Lluque A, Mosquito S, Gomes C, Riveros M, Durand D, Tilley DH, et al. Virulence factors and mechanisms of antimicrobial resistance in Shigella strains from periurban areas of lima (Peru). International Journal of Medical Microbiology. 2015;305(4):480-90.

9. Bercion R, Demartin M, Recio C, Massamba P-M, Frank T, Escribà JM, et al. Molecular epidemiology of multidrug-resistant Shigella dysenteriae type 1 causing dysentery outbreaks in Central African Republic, 2003-2004. Trans R Soc Trop Med Hyg. 2006;100(12):1151-8.

10. Kumar R, Umar A, Kumar G, Nalwa HS. Antimicrobial properties of ZnO Nanomaterials: a review. Ceram Int. 2017;43(5):3940-61.

11. Cavera VL, Arthur TD, Kashtanov D, Chikindas ML. Bacteriocins and their position in the next wave of conventional antibiotics. Int J Antimicrob Agents. 2015;46(5):494-501.

12. Sportelli MC, Picca RA, Cioffi N. Recent advances in the synthesis and characterization of nano-antimicrobials. TrAC Trends Anal Chem. 2016; 84(part A):131-8.

13. Castonguay A, Ladd E, van de Ven TG, Kakkar A. Dendrimers as bactericides. New J Chem. 2012;36(2):199-204

14. Xue X, Chen X, Mao X, Hou Z, Zhou Y, Bai H, et al. Amino-terminated generation 2 poly (amidoamine) dendrimer as a potential broad-spectrum, nonresistance-inducing antibacterial agent. AAPS J. 2013;15(1):132-42.
15. Charles S, Vasanthan N, Kwon D, Sekosan G, Ghosh S. Surface modification of poly (amidoamine)(PAMAM) dendrimer as antimicrobial agents. Tetrahedron Lett. 2012;53(49):6670-5.

16. Wang B, Navath RS, Menjoge AR, Balakrishnan B, Bellair R, Dai H. Inhibition of bacterial growth and intramniotic infection in a guinea pig model of chorioamnionitis using PAMAM dendrimers. Int J Pharm. 2010;395(1):298-308.

17. Calabretta MK, Kumar A, McDermott AM, Cai C. Antibacterial activities of poly (amidoamine) dendrimers terminated with amino and poly (ethylene glycol) groups. Biomacromolecules. 2007;8(6):1807-11.

18. Strydom SJ, Rose WE, Otto DP, Liebenberg W, De Villiers MM. Poly (amidoamine) dendrimer-mediated synthesis and stabilization of silver sulfonamide nanoparticles with increased antibacterial activity. Nanomedicine: nanotechnology, biology and medicine. 2013;9(1):85-93.

19. Maiti PK, Cagin T, Wang G, Goddard WA. Structure of PAMAM dendrimers: generations 1 through 11. Macromolecules. 2004;37(16):6236-54.

20. Majoros IJ, Myc A, Thomas T, Mehta CB, Baker JR. PAMAM dendrimer-based multifunctional conjugate for cancer therapy: synthesis, characterization, and functionality. Biomacromolecules. 2006;7(2):572-9.

21. Clinical and Laboratory Standards Institute. Performance standards for antimicrobial susceptibility testing; twenty-fourth informational supplement. Document M100-S24. Wayne, PA: CLSI; 2014.

22. Mukherjee SP, Lyng FM, Garcia A, Davoren M, Byrne HJ. Mechanistic studies of in vitro cytotoxicity of poly (amidoamine) dendrimers in mammalian cells. Toxicol Appl Pharmacol. 2010;248(3):259-68.

23. Tajeddin E, Rashidan M, Razaghi M, Javadi SS, Sherafat SJ, Alebouyeh M, et al. The role of the intensive care unit environment and health-care workers in the transmission of bacteria associated with hospital acquired infections. Journal of infection and public health. 2016;9(1):13-23.

24. Felczak A, Wrońska N, Janaszewska A, Klajnert B, Bryszewska M, Appelhans D, et al. Antimicrobial activity of poly (propylene imine) dendrimers. New J Chem. 2012;36(11):2215-22.

25. Adhikari RP, Thompson CD, Aman MJ, Lee JC. Protective efficacy of a novel alpha hemolysin subunit vaccine (AT62) against Staphylococcus aureus skin and soft tissue infections. Vaccine. 2016;34(50):6402-7.

26. De Vos D, Pirnay J-P, Bilocq F, Jennes S, Verbeken G, Rose T, et al. Molecular epidemiology and clinical impact of Acinetobacter calcoaceticus-baumannii complex in a Belgian burn wound center. PLoS One. 2016;11(5):1-26.

27. Cho S-H, Oh K-H, Kim S-H, Oh H-B, Park M-S. Distribution of virulence genes and their Association of Serotypes in pathogenic Escherichia coli isolates from diarrheal patients in Korea. Osong Public Health and Research Perspectives. 2010;1(1):29-35

28. Hsieh W-S, Yang $Y-Y$, Yang $H-Y$, Huang $Y$-S, Wu H-H. Recombinant outer membrane protein a fragments protect against Escherichia coli meningitis. J Microbiol Immunol Infect. 2014;49(3):329-34.

29. Khanam S, Guragain M, Lenaburg DL, Kubat R, Patrauchan MA. Calcium induces tobramycin resistance in Pseudomonas Aeruginosa by regulating RND efflux pumps. Cell Calcium. 2017:61:32-43.

30. Campos AC, Albiero J, Ecker AB, Kuroda CM, Meirelles LE, Polato A, et al. Outbreak of Klebsiella pneumoniae carbapenemase-producing $\mathrm{K}$ pneumoniae: a systematic review. Am J Infect Control. 2016;44(11):1374-80.

31. Raja SB, Murali MR, Devaraj SN. Differential expression of ompC and ompF in multidrug-resistant Shigella dysenteriae and Shigella flexneri by aqueous extract of Aegle marmelos, altering its susceptibility toward $\beta$-lactam antibiotics. Diagn Microbiol Infect Dis. 2008;61(3):321-8.

32. Loison P, Gervais P, Perrier-Cornet J-M, Kuimova MK. Effect of ethanol perturbation on viscosity and permeability of an inner membrane in Bacillus Subtilis spores. Biochimica et Biophysica Acta (BBA)-Biomembranes. 2016; 1858(9):2060-9.

33. Izanloo H, Ahmadi Jebelli M, Nazari S, Tashauoei H. Studying the antibacterial effect of polyamidoamine-G4 dendrimer on some of the gramnegative and gram-positive bacteria. J Arak Univ Med Sci. 2014;17(90):1-10.

34. Izanloo $\mathrm{H}$, Ahmamado Jabali M, Tashyiee $\mathrm{H}$, Khazaee M, Nazari S. The antimicrobial effects of Polypropylenimine-G2 and Polyamidoamine-G4 dendrimers on Klebsiella oxytoca, Pseudomonas Aeruginosa and Proteus Mirabilis, in vitro experiment. J Sabzevar Univ Med Sci. 2014;21(5):925-33.

35. Hermanson GT. Bioconjugate techniques: Third ed. San Diego: Academic Press; 2013.

36. Chen $C Z$, Cooper SL. Interactions between dendrimer biocides and bacterial membranes. Biomaterials. 2002;23(16):3359-68.

37. Mah T-FC, O'Toole GA. Mechanisms of biofilm resistance to antimicrobial agents. Trends Microbiol. 2001;9(1):34-9. 
38. Chen CZ, Cooper SL. Recent advances in antimicrobial dendrimers. Adv Mater. 2000;12(11):843-6.

39. Breidenstein $E B$, de la Fuente-Núñez C, Hancock RE. Pseudomonas aeruginosa: all roads lead to resistance. Trends Microbiol. 2011;19(8):419-26.

40. Rajamohan G, Srinivasan VB, Gebreyes WA. Molecular and functional characterization of a novel efflux pump, AmvA, mediating antimicrobial and disinfectant resistance in Acinetobacter Baumannii. J Antimicrob Chemother. 2010;65(9):1919-25.

41. Hong S, Bielinska AU, Mecke A, Keszler B, Beals JL, Shi X. Interaction of poly (amidoamine) dendrimers with supported lipid bilayers and cells: hole formation and the relation to transport. Bioconjug Chem. 2004;15(4):774-82.

42. Hong S, Leroueil PR, Janus EK, Peters JL, Kober M-M, Islam MT. Interaction of polycationic polymers with supported lipid bilayers and cells: nanoscale hole formation and enhanced membrane permeability. Bioconjug Chem. 2006:17(3):728-34

43. Sadekar S, Ghandehari H. Transepithelial transport and toxicity of PAMAM dendrimers: implications for oral drug delivery. Adv Drug Deliv Rev. 2012; 64(6):571-88.

44. Luong D, Kesharwani P, Deshmukh R, Amin MCIM, Gupta U, Greish K, et al. PEGylated PAMAM dendrimers: enhancing efficacy and mitigating toxicity for effective anticancer drug and gene delivery. Acta Biomater. 2016;43:14-29.

45. Bodewein L, Schmelter F, Di Fiore S, Hollert H, Fischer R, Fenske M. Differences in toxicity of anionic and cationic PAMAM and PPI dendrimers in zebrafish embryos and cancer cell lines. Toxicol Appl Pharmacol. 2016;305:83-92.

\section{Submit your next manuscript to BioMed Central and we will help you at every step:}

- We accept pre-submission inquiries

- Our selector tool helps you to find the most relevant journal

- We provide round the clock customer support

- Convenient online submission

- Thorough peer review

- Inclusion in PubMed and all major indexing services

- Maximum visibility for your research

Submit your manuscript at www.biomedcentral.com/submit 